\title{
CASCADE REFRIGERATION SYSTEM FOR LOW TEMPERATURES USING NATURAL FLUIDS
}

\author{
V. B. Rangel, \\ and A. G. S. Almeida \\ Instituto Federal da Bahia \\ Departamento Acadêmico de Tecnologia \\ Mecânica \\ Campus de Salvador \\ Salvador, Bahia, Brasil \\ victorrangel@ifba.edu.br \\ gabrielalmeida@ifba.edu.br \\ Received: Nov 11, 2020 \\ Revised: Jun 10, 2021 \\ Accepted: Jun 16, 2021 \\ $\mathrm{c}_{\mathrm{p}} \quad$ fluid specific heat at constant pressure, $\mathrm{J} /(\mathrm{kg} . \mathrm{K})$ \\ COP coefficient of performance \\ $\frac{d \mathrm{E}_{\mathrm{vc}}}{d t} \quad$ exergy flow rate of a control volume \\ $\dot{\mathrm{E}}_{\mathrm{d}} \quad$ exergy destruction flow rate \\ EES Engineering Equation Solver \\ GWP Global Warming Potential \\ ODP Ozone Depletion Potential \\ Q overall heat transfer rate, $\mathrm{W}$ \\ $\mathrm{T}$ average fluid temperature, $\mathrm{K}$ \\ $\mathrm{W}$ energy transfer by work flow rate
}

\section{ABSTRACT}

Cascade refrigeration systems work with two or more serial disposed cycles and can obtain internal temperatures below $-60^{\circ} \mathrm{C}$, which is necessary for several activities in medicine and scientific research. This paper presents a thermodynamic analysis of cascade system refrigeration using natural refrigerant fluids for ultra-low temperatures. These fluids are environmentally friendly refrigerant and are an alternative to hydro chlorofluorocarbons (HCFCs) and to hydrofluorocarbons (HFCs). Energy and exergy analyses were performed using a thermodynamic model based on the law of conservation of mass and also on the first and second laws of thermodynamics. A simulator was developed to assess the technical practicability of this system, considering it running as a real refrigeration cycle. Natural fluids have best performance energetically and environmentally.

Keywords: exergy; cascade refrigeration; natural refrigerant fluids; real refrigeration cycle

\section{NOMENCLATURE}

CFC chlorofluorocarbons

e, ex specific exergy

g gravity, $\mathrm{m} / \mathrm{s}^{2}$

h specific enthalpy

$\mathrm{HC}$ hydrocarbons

HCFC hydrochlorofluorocarbons

HFC hydrofluorocarbons

m mass flow rate, $\mathrm{kg} / \mathrm{s}$

$\mathrm{p}$ pressure, $\mathrm{N} / \mathrm{m}^{2}$

S specific entropy

$\mathrm{t}$ time, $\mathrm{s}$

$\mathrm{V} \quad$ specific volum

$\frac{d \mathrm{~V}_{\mathrm{vc}}}{d t} \quad$ volume flow rate

\section{Subscripts}

0 dead state

casc cascade exchanger cond condenser

compH high temperature compressor

compL low temperature compressor

e inlet

evap evaporator

expH high temperature expansion valve

expL low temperature expansion valve

$\mathrm{H}$ high temperature cycle

i ideal

L low temperature cycle

o outlet

$r$ real

$\mathrm{S}$ isentropic

vc control volume

\section{INTRODUCTION}

Cascade refrigeration systems are usually used in applications with temperatures below $-60{ }^{\circ} \mathrm{C}$. Such systems are composed of independent cycles, each one with its own refrigerant, but they have a heat exchanger in common. The main advantage of multistage refrigeration cycles is that cycles do not contain the same refrigerant fluid therefore they do not need to operate at both higher and lower pressure levels (Park et al, 2013).

Cascade systems usually operate using synthetic refrigerants such as HCFC and HFC, which are currently being replaced by natural or ecological fluids for environmental reasons. Cascade refrigeration systems using natural refrigerants are therefore an 
ecologically relevant alternative (Bayrakçi et al, 2009).

The theoretical analysis of thermal systems and processes have historically been based on the application of the laws of conservation of mass, momentum and energy. The energy performance of refrigerant systems is usually evaluated based on the first law of Thermodynamics. However, compared to energy analysis, exergy analysis can better and more accurately show the location of inefficiencies. The exergy method is a technique in which the basis of evaluation of thermodynamic losses follows the second law rather than the first law of Thermodynamics. The results from exergy analysis can be used to assess and optimize the performance of refrigerant systems (Ahamed et al, 2011).

Alhamid et al. (2010) analyzed an azeotrope mixture carbon dioxide and ethane-propane (R744+R170-R290) cascade system thermodynamically for low temperatures. Their results show that evaporating and condensing temperatures have strong effects on COP and the mass flow ratios of the system. Aminyavariet al. (2014) modeled and analyzed a $\mathrm{CO}_{2} / \mathrm{NH}_{3}$ cascade refrigeration system from energetic, exergetic, economic and environmental viewpoints and validated the developed model using the result of a previous study.

Di Nicola et al. (2011) investigated the performance of cascade cycles working with blends of $\mathrm{CO} 2+$ natural refrigerants and their results show that COP of the cascade cycle with the studied R744 blends reach acceptable values, even if a better performance is achieved using pure HCs refrigerants in a low stage of cascade systems. The interest in considering such blends is related to the lower environmental impact of R744 and particularly to its ability to reduce HCs flammability.

Kilicarslan and Hosoz (2010) performed an energy and irreversibility analysis of a cascade refrigeration system for various refrigerant couples (R152a-R23， R290-R23， R507-R23， R234a-R23, R717-R23 and R404a-R23) and found that the refrigerant couple R717-R23 is the best for vapor compression cascade refrigeration systems among all considered couples.

Hwang et al. (2007) compared R-290 and two HFC blends for walk-in refrigeration systems considering the safety, environmental impact, cost and performance of these fluids. Corberán et al. (2008) revised the standards for the use of hydrocarbon refrigerants in $\mathrm{A} / \mathrm{C}$, heat pump and refrigeration equipment. Ahamed et al. (2011) also did a review on exergy analysis of vapor compression refrigeration system showing that the maximum exergy losses occur in compressor among the components of the vapor compression refrigeration system. They suggest that the use of nanolubricants can reduce the friction coefficient and it can therefore increase the exergy efficiency of the compressor.
Kabul et al. (2008) performed an exergetic analysis of vapor refrigeration system with an internal heat exchanger using a hydrocarbon, isobutane, while Bayrakçi et al. (2009) performed an energy and exergy analysis of a vapor compression refrigeration system using pure hydrocarbon refrigerants. Their results show that hydrocarbons perform well and can be used to replace $\mathrm{CFC}$ and $\mathrm{HCFC}$.

In this paper, the main objective is to perform an assessment of the energy and exergy point of view of a cascade refrigeration system for low temperatures using natural fluids. It is possible to determine process efficiencies based on the first and second laws of thermodynamics and the thermodynamic properties of working fluids. Simulations were performed on the Engineering Equation Solver (EES) platform, considering the operational conditions as a not-ideal refrigeration system, characterized by having a subcooled fluid at the condenser's output, an overheated fluid at the compressor's input, the compressor's efficiency, and also external influences as a way to assess the technical feasibility of the system's implementation. The results are expected to show that $\mathrm{HC}$ are more efficient than synthetic fluids when used in the analyzed system.

\section{THEORY}

\section{Cascade refrigeration system}

A cascade refrigeration system consists of at least two refrigeration cycles working independently. Both refrigeration cycles are connected by a cascade heat exchanger where heat is released in a low-temperature circuit condenser and is absorbed by a hightemperature circuit evaporator (Alhamid et al., 2010).

The desired refrigeration effect occurs in the lowtemperature evaporator, and heat rejection from the system as a whole takes place in the high-temperature condenser.

The cascade system can resolve several problems coming from the high-pressure ratio in low temperature refrigeration systems. In systems in which the same refrigerant passes through the stages of high and low temperatures, extreme values of pressure and specific volume can cause problems. In fact, when the evaporation temperature is too low, the specific volume of refrigerant vapor in the compressor suction is high, which implies a high volumetric capacity compressor (Park et al, 2013).

Regarding pressure, an important aspect of the cascade system is that the refrigerant in two or more stages can be selected to reasonable pressures in the evaporator and the condenser in two or more temperature intervals.

In a double cascade system (Fig. 1), a refrigerant for the cycle A must have such a relationship between the saturation pressure and temperature that enables refrigeration at a relatively low temperature without any excessively low pressure in the evaporator. The 
refrigerant in cycle $B$ must have saturation characteristics that allow condensation to the desired temperature in the absence of excessively high pressures in the condenser.

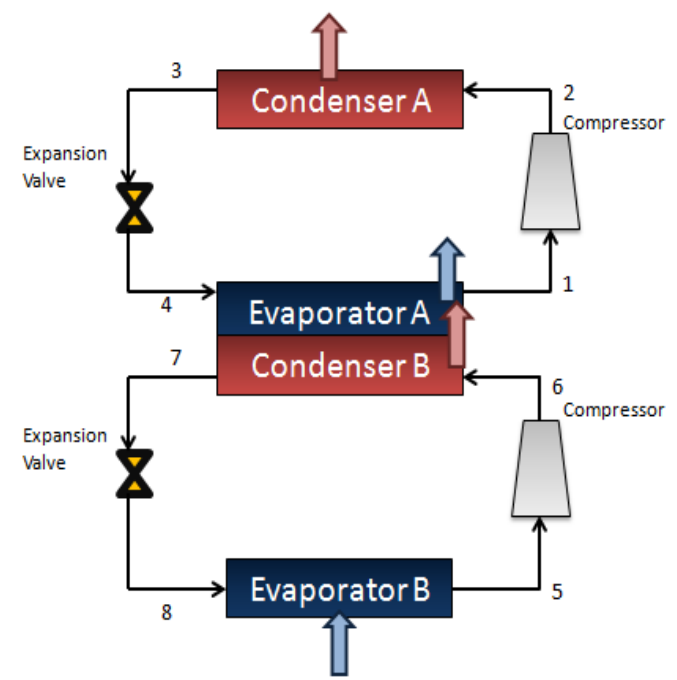

Figure1. Cascade refrigeration system

\section{Exergy}

The exergetic analysis is a thermodynamic tool that can be used to evaluate the performance of refrigeration cycles determining the magnitude and location of process irreversibilities (losses of energy quality), making possible to study the changes of operational variables of the process, aiming an economy of energy consumption. With this analysis it is possible to evaluate the individual performance of each equipment or the general performance of the entire process (Fabrega et al.,2010).

However, exergy can not only be destroyed by irreversibilities, but it can also be transferred to other systems. The exergy transferred from one system to its surroundings and which is not used usually represents a loss. Better use of energy resources is possible by decreasing the system's exergy destruction and / or reducing losses (Kotas, 1995).

The balance of exergy of a control volume is presented by (1) (Szargut, 1998):

$$
\begin{aligned}
\frac{\mathrm{dE}_{\mathrm{vc}}}{\mathrm{dt}}=\sum_{\mathrm{j}}\left(1-\frac{\mathrm{T}_{0}}{\mathrm{~T}_{\mathrm{j}}}\right) \dot{\mathrm{Q}}_{\mathrm{j}}-\left(\dot{\mathrm{W}}_{\mathrm{vc}}-\mathrm{p}_{0} \frac{\mathrm{dV}_{\mathrm{vc}}}{\mathrm{dt}}\right)+ \\
\sum_{\mathrm{e}} \dot{\mathrm{m}}_{\mathrm{e}} \mathrm{e}_{\mathrm{fe}}-\sum_{\mathrm{s}} \dot{\mathrm{m}}_{\mathrm{s}} \mathrm{e}_{\mathrm{fs}}-\dot{\mathrm{E}}_{\mathrm{d}}
\end{aligned}
$$

where $\left(\frac{\mathrm{dE}_{\mathrm{vc}}}{\mathrm{dt}}\right)$ is exergy flow rate of a control volume, the terms $\left(1-\frac{T_{0}}{T_{j}}\right) \dot{Q}_{j}$ represent the exergy flow transfer accompanying the heat transfer rate $\dot{\mathrm{Q}}_{\mathrm{j}}$, which occurs at border points where instantaneous temperature is $\mathrm{T}_{\mathrm{j}} . \dot{\mathrm{W}}_{\mathrm{vc}}$ represents the energy transfer by work flow rate of a control volume and the exergy flow rate transfer is given by $\dot{W}_{\mathrm{vc}}-\mathrm{p}_{0} \frac{\mathrm{dV}_{\mathrm{vc}}}{\mathrm{dt}}$, where $\frac{d v_{v c}}{d t}$ is the volume flow rate. The terms $\left(\sum_{\mathrm{e}} \dot{\mathrm{m}}_{\mathrm{e}} \mathrm{e}_{\mathrm{fe}}-\right.$ $\left.\sum_{s} \dot{m}_{s} e_{f s}\right)$ represent the exergy transfer with mass input and output of the control volume, respectively. $\dot{\mathrm{E}}_{\mathrm{d}}$ is the exergy destruction flow rate due to irreversibility.

In steady state, $\frac{\mathrm{dE}_{\mathrm{vc}}}{\mathrm{dt}}=\frac{\mathrm{dV}_{\mathrm{vc}}}{\mathrm{dt}}=0$, thus obtaining the exergy balance for the steady state in terms of rate,

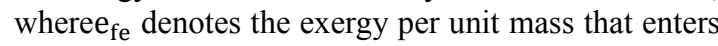
and traverses, the $\mathrm{e}_{\mathrm{fs}}$ denotes the exergy per unit mass passing through the exit. These terms, known as specific exergy flow, are expressed by:

$$
e_{f}=h-h_{0}-T_{0}\left(s-s_{0}\right)+\frac{v^{2}}{2}+g z
$$

where $\mathrm{h}$ and $\mathrm{s}$ represent specific enthalpy and entropy, respectively, at the inlet or outlet considered; $h_{0}$ and $\mathrm{s}_{0}$ represent the respective values of these properties when evaluated in $T_{0}, P_{0}$, temperature and pressure in dead state.

\section{Refrigerant fluids}

Since the Montreal Protocol, the refrigeration industry has sought substitutes for $\mathrm{CFC}$ and $\mathrm{HCFC}$ refrigerants. The use of hydrocarbons (HC) as refrigerants in some applications of refrigeration and air conditioning has been a valid alternative. Compared with CFC, hydrochorofluocarbons (HCFC) and hydrofluorocarbons (HFC), hydrocarbons refrigerants offer zero Ozone Depletion Potential (ODP) and extremely low Global Warming Potential (GWP) and, in regard to their performance, they offer in general: high efficiency, reduces charge sizes, good miscibility with mineral oils (synthetic lubricants are not required), lower compressor discharge temperatures, and slightly better heat transfer within heat exchangers (Corberan et al., 2008).

From the hydrocarbons, isobutane (R600a) is the most frequently used refrigerant, been dominant in Europe with a market share of more than $95 \%$ in household refrigerators. Propane (R290) and propylene (R1270) are used by many heat pump manufacturers, and have also been used in air conditioners and commercial refrigeration systems (Palm, 2008). Ethylene (R-1150) is one of the most important raw materials in the petrochemical industry and is used in the synthesis of a series of products such as: ethylene oxide, ethylene glycol, ethyl alcohol, polyethylene, and polystyrene. It is used, mixed with nitrogen, to accelerate fruits ripening.

The cascade systems currently still use refrigerant fluids with high GWP, such as R-508B and $\mathrm{R}-404 \mathrm{a}$. These fluids are HFCs, are not inflammable and have low toxicity. In cascade systems, R-404A is 
refrigerant fluid at high temperature cycle and R-508B refrigerant fluid at low temperature cycle.

While the hydrocarbons have values of global warming potential (GWP) near 3, the GWP value $\left(\mathrm{CO}_{2}\right.$ $=1$ ) of R-508B is 10350 and R-404A is 3260 (Hansen et al., 2000).

Therefore, hydrocarbons can be relevant substitutes for these systems, being technically feasible and can operate over a wide range of evaporation temperature (until the lower limit of $170^{\circ} \mathrm{C}$ ). However, practical applications are restricted by security codes and national regulation because they are flammable fluids. Thus, appropriate safety measures should be used during handling, fabrication, maintenance and servicing and at the final disposal of the equipment.

\section{NUMERICAL METHOD}

In the modeling of cascade refrigeration system (Fig. 1), some assumptions were adopted to perform exergy analysis:

- $\quad$ All systems operating at steady state;

- Negligible pressure and heat losses/gains in the pipe networks or system components;

- Variation of kinetic and potential energies in every equipment neglected;

- Isenthalpic expansion in expansion valve.

$\mathrm{T}-\mathrm{S}$ diagram of the refrigeration cycle is shown in Fig. 2, where the symbols "i", "r" and "s" mean ideal, real and isentropic processes respectively. In the diagram, corresponding to high temperature cycle (Fig. 1), 1i-1r is over heating at compressors input; 1r$2 \mathrm{~s}$ is isentropic compression on the compressor, and $1 \mathrm{r}-2$ is the real process of compression due to the compressors efficiency; $2-3 \mathrm{i}$ is condensation; $3 \mathrm{i}-3 \mathrm{r}$ is sub cooling at expansion valve's input; 3r-4is throttling on the expansion valve; and 4liisevaporation.The same occurs for the low temperature cycle.

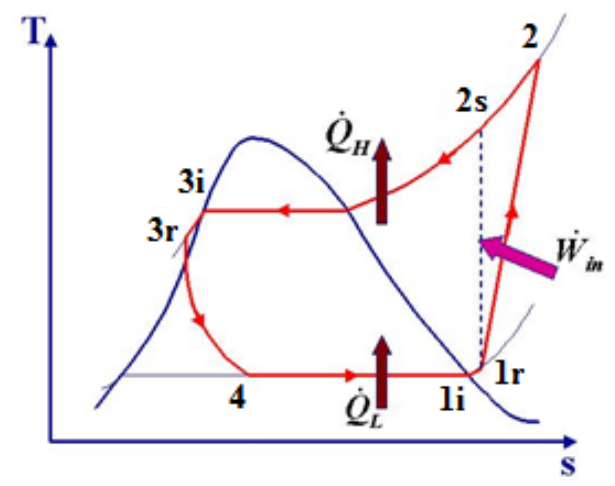

Figure 2. T-S diagram of real vapor compression refrigeration system
Balances of mass, energy and exergy were applied for the control volumes of the cycles of high (Cycle A, Fig. 1) and low temperature (Cycle B, Fig. 1): condenser, expansion valve, compressor, and evaporator. The obtained equations are:

High Compressor

$$
\begin{array}{r}
\dot{\mathrm{m}}_{2}=\dot{\mathrm{m}}_{1} \\
\dot{\mathrm{W}}_{\mathrm{Hl}}=\dot{\mathrm{m}}_{1}\left(\mathrm{~h}_{2 \mathrm{~s}}-\mathrm{h}_{1}\right) \\
\dot{\mathrm{W}}_{\mathrm{Hr}}=\dot{\mathrm{m}}_{1}\left(\mathrm{~h}_{2}-\mathrm{h}_{1}\right) \\
\mathrm{E}_{\mathrm{dcompH}}=\mathrm{W}_{\mathrm{Hr}}+\dot{\mathrm{m}}_{1}\left(\mathrm{ex}_{1}-\mathrm{ex}_{2}\right)
\end{array}
$$

High Condenser

$$
\begin{gathered}
\dot{\mathrm{m}}_{3}=\dot{\mathrm{m}}_{2} \\
\mathrm{Q}_{\text {cond }}=\dot{\mathrm{m}}_{3}\left(\mathrm{~h}_{3}-\mathrm{h}_{2}\right) \\
\mathrm{E}_{\mathrm{dcond}} \cdot \dot{\mathrm{m}_{2}}\left(\mathrm{ex}_{2}-\mathrm{ex}_{3}\right)
\end{gathered}
$$

High Expansion Valve

$$
\begin{gathered}
\dot{\mathrm{m}}_{4}=\dot{\mathrm{m}}_{3} \\
\mathrm{~h}_{4}=\mathrm{h}_{3} \\
\mathrm{E}_{\mathrm{dexpH}}=\dot{\mathrm{m}}_{3}\left(\mathrm{ex}_{3}-\mathrm{ex}_{4}\right)
\end{gathered}
$$

Cascade Exchanger

$$
\begin{gathered}
\dot{\mathrm{m}}_{1}=\dot{\mathrm{m}}_{4} \\
\dot{\mathrm{m}}_{7}=\dot{\mathrm{m}}_{6} \\
\mathrm{Q}_{\text {casc }}=\mathrm{m}_{4}\left(\mathrm{~h}_{1}-\mathrm{h}_{4}\right)=\dot{\mathrm{m}}_{7}\left(\mathrm{~h}_{7}-\mathrm{h}_{6}\right) \\
\mathrm{E}_{\text {dcasc }}=\dot{\mathrm{m}}_{4}\left(\mathrm{ex}_{4}-\mathrm{ex}_{1}\right)-\dot{\mathrm{m}}_{7}\left(\mathrm{ex}_{7}-\mathrm{ex}_{6}\right)
\end{gathered}
$$

Low Compressor

$$
\begin{gathered}
\dot{\mathrm{m}}_{6}=\dot{\mathrm{m}}_{5} \\
\mathrm{~W}_{\text {Lideal }}^{\cdot}=\dot{\mathrm{m}}_{5}\left(\mathrm{~h}_{6 \mathrm{~s}}-\mathrm{h}_{5}\right) \\
\mathrm{W}_{\text {Lreal }}^{\cdot}=\dot{\mathrm{m}}_{5}\left(\mathrm{~h}_{6}-\mathrm{h}_{5}\right) \\
\mathrm{E}_{\mathrm{dcompL}}=\dot{\mathrm{W}}_{\mathrm{Lr}}+\dot{\mathrm{m}}_{5}\left(\mathrm{ex}_{5}-\mathrm{ex}_{6}\right)
\end{gathered}
$$

Low Evaporator

$$
\begin{gathered}
\dot{m}_{8}=\dot{m}_{5} \\
\dot{Q_{E}}=\dot{m}_{5}\left(h_{5}-h_{8}\right)
\end{gathered}
$$




$$
\mathrm{E}_{\text {devap }}=-\left[\dot{Q_{\mathrm{e}}}\left(1-\frac{\mathrm{T}_{0}}{\mathrm{~T}_{5}}\right)\right]+\dot{\mathrm{m}}_{8}\left(\mathrm{ex}_{8}-\mathrm{ex}_{5}\right)
$$

Low Expansion Valve

$$
\begin{gathered}
\dot{\mathrm{m}}_{8}=\dot{\mathrm{m}}_{7} \\
\mathrm{~h}_{8}=\mathrm{h}_{7} \\
\mathrm{E}_{\mathrm{dexpL}}=\dot{\mathrm{m}}_{7}\left(\mathrm{ex}_{7}-\mathrm{ex}_{8}\right)
\end{gathered}
$$

And:

$$
\begin{aligned}
& \operatorname{COP}_{\text {casc }}=\dot{\mathrm{Q}}_{\mathrm{E}} / \dot{\mathrm{W}}_{\mathrm{H}_{\mathrm{r}}}+\dot{\mathrm{W}}_{\mathrm{L}_{\mathrm{r}}} \\
& \mathrm{e}_{\text {compL }}=\left(\mathrm{h}_{6 \mathrm{~s}}-\mathrm{h}_{5}\right) /\left(\mathrm{h}_{6}-\mathrm{h}_{5}\right) \\
& \mathrm{e}_{\text {compH }}=\left(\mathrm{h}_{2 \mathrm{~s}}-\mathrm{h}_{1}\right) /\left(\mathrm{h}_{2}-\mathrm{h}_{1}\right)
\end{aligned}
$$

where $\dot{\mathrm{m}}$ is mass flow rate, $\mathrm{P}$ is pressure, $\mathrm{T}$ is temperature, $\dot{W}$ is work rate, $\mathrm{h}$ is specific enthalpy, $\mathrm{h}_{\mathrm{s}}$ is isenthalpic specific enthalpy, ex is specific exergy, $\dot{E}_{\mathrm{d}}$ is exergy destruction rate, $\dot{Q}$ is heat transfer rate, $\mathrm{COP}$ is coefficient of performance, $\mathrm{T}_{0}$ is an environmental input parameter, $\mathrm{e}_{\text {comp }}$ is compressor's efficiency obtained in manufacturer's datasheets and $\mathrm{h}_{\mathrm{x}}$ are enthalpy in compressor's input and output states.

\section{Fluid Selection}

The refrigerant fluids selection for thermodynamic modeling was performed by their physical properties analysis, observing critical temperatures and pressures. On cascade refrigeration system, the evaporation temperature of the refrigerant in low temperature cycle is $-92^{\circ} \mathrm{C}$ and the condensation temperature was established $-30^{\circ} \mathrm{C}$ as medium value, so that the temperature and pressure difference wouldn't be very high, so a high compression ratio wouldn't be necessary. Therefore, the average evaporation temperature of the refrigerant in high temperature cycle is $-30^{\circ} \mathrm{C}$ and condensation temperature $45^{\circ} \mathrm{C}$.

Thus, we sought fluids to work at those temperatures with pressures above atmospherics' so as to avoid negative values of pressure. Analyzing the pressure values at the established temperatures, it was discovered that ethylene is the refrigerant which best suits the conditions of low temperature cycle, and propylene and propane best suited the high temperature cycle conditions (ASHRAE, 2000).

Knowing that propane is a refrigerant fluid whose use is more common compared to the others, it was selected for the high temperature circuit.

For the low temperature circuit, ethylene and ethane were chosen to test, even though the last one works below atmospheric pressure.

\section{Simulation}

The simulation was modeled on EES (Engineering Equation Solver) software, where a thermal load value to be removed by the cascade system was estimated at $800 \mathrm{~W}$, a value corresponding to a commercial freezer for ultra-low temperatures.

All refrigerant thermo physical properties were obtained from the EES database, for several state points as shown in Fig. 1 and Fig. 2 and are directly calculated in the system analysis program.

The input parameters for the simulation of the system's thermodynamic model are:

- $\mathrm{T}_{0}: 35^{\circ} \mathrm{C}$

- $\mathrm{P}_{0}: 101 \mathrm{kPa}$

- Evaporation temperature of low cycle: $-92^{\circ} \mathrm{C}$

- Evaporation temperature of high cycle: $-35^{\circ} \mathrm{C}$

- Condensation temperature of the high temperature cycle: $45^{\circ} \mathrm{C}$

- Condensation temperature of the low temperature cycle: $-25^{\circ} \mathrm{C}$

- Cycle A compressor's efficiency: 0.56

- Cycle B compressor's efficiency: 0.70

\section{RESULTS AND DISCUSSION}

Computational model is developed in engineering equation solver (EES) using fluid pairs R404a - R508b, propane-ethyleneand propane-ethane to obtain comparison parameters.

Table 1 shows energy consumption on compressors (W), heat transfer on condensers and evaporators $(\mathrm{Q})$, coefficient of performance (COP), coefficient of performance of the cascade system (COPcas), and destroyed exergy on every component (Ed). Results are shown for both high and low temperature cycles. Results obtained by fixing the condensation temperature of the high temperature cycle at $45^{\circ} \mathrm{C}$, and maintaining system's cooling power at around $800 \mathrm{~W}$.

Results at Table 1 show that the added energy consumption $\left(\mathrm{W}_{\mathrm{H}}+\mathrm{W}_{\mathrm{L}}\right)$ of propane-ethylene and propane-ethane are $7 \%$ and $12 \%$ lower than the synthetic pair's, respectively. Destructed exergy $\left(E_{d}\right)$ are lower on $\mathrm{HCs}$ on most components, at the exception of the cascade system and low temperature cycle compressor for the ethylene pair only. Comparing overall destructed exergy results, propane - ethylene and propane - ethane have $7 \%$ and $12 \%$ lower values than R404a - R508b.

Table 1 - Output values of the EES simulation

\begin{tabular}{c|c|c|c}
\hline $\begin{array}{c}\text { Output } \\
(\mathrm{kW})\end{array}$ & $\begin{array}{c}\text { R404a } \\
\mathrm{R} 508 \mathrm{~b}\end{array}$ & $\begin{array}{c}\text { Propane } \\
\text { Ethylene }\end{array}$ & $\begin{array}{c}\text { Propane } \\
\text { Ethane }\end{array}$ \\
\hline $\mathrm{W}_{\text {Hideal }}$ & 0.8028 & 0.7019 & 0.6773 \\
\hline $\mathrm{W}_{\text {Lideal }}$ & 0.427 & 0.4444 & 0.4094 \\
\hline $\mathrm{Q}_{\mathrm{c}}$ & 2.846 & 2.691 & 2.596 \\
\hline $\mathrm{Q}_{\text {casc }}$ & 1.412 & 1.437 & 1.387 \\
\hline
\end{tabular}




\begin{tabular}{c|c|c|c}
\hline $\mathrm{Q}_{\mathrm{e}}$ & 0.8004 & 0.8026 & 0.8019 \\
\hline $\mathrm{COP}_{\mathrm{cas}}$ & 0.6509 & 0.7001 & 0.7379 \\
\hline $\mathrm{E}_{\text {dcompH }}$ & 2.312 & 2.030 & 1.959 \\
\hline $\mathrm{E}_{\text {dcompL }}$ & 1.033 & 1.102 & 1.008 \\
\hline $\mathrm{E}_{\text {dcond }}$ & 0.1532 & 0.1466 & 0.1414 \\
\hline $\mathrm{E}_{\text {devapL }}$ & 0.002178 & 0.001558 & 0.001500 \\
\hline $\mathrm{E}_{\text {dexpH }}$ & 0.3046 & 0.2080 & 0.2007 \\
\hline $\mathrm{E}_{\text {dexpL }}$ & 0.14010 & 0.11990 & 0.09954 \\
\hline $\mathrm{E}_{\text {dcas }}$ & 0.1448 & 0.2076 & 0.1693 \\
\hline $\mathrm{E}_{\text {dtotal }}$ & 4.090 & 3.815 & 3.579
\end{tabular}

Fig. 3 shows high temperature cycle's condensation temperature versus system's energy consumption. The HC present an almost linear growth of energy consumption with growing temperature. Ethane pair present slightly lower energy consumption than ethylene's. For the R404a - R508b, its energy consumption grows linear for temperatures below $40^{\circ} \mathrm{C}$, but for temperatures greater than that, it starts to grow exponentially. When the condensation temperature is $65^{\circ} \mathrm{C}$, $\mathrm{HC}$ have energy consumption around $1.5 \mathrm{~kW}$ and $\mathrm{R} 404 \mathrm{a}-\mathrm{R} 508 \mathrm{~b}$ around $2 \mathrm{~kW}$, which is almost $33 \%$ higher than HC. So, HC have better efficiency than R404a - R508b for high condensation temperatures.

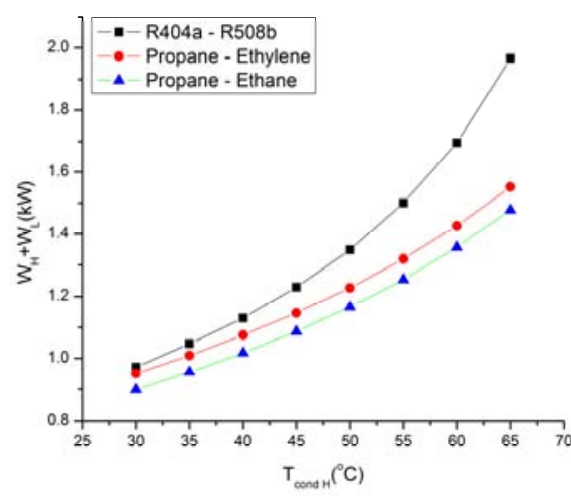

Figure 3. High temperature cycle's condensation temperature $\mathrm{x}$ Energy consumption

Fig. 4 shows exergy destruction per component and the added exergy destruction per fluid pair. The exergy destruction is concentrated on the compressors, as they have values around $1 \mathrm{~kW}$ for the low cycle compressor, and around $2 \mathrm{~kW}$ for the high cycle, while the other components barely reach $0.25 \mathrm{~kW}$ each.

Results at Fig. 4 show that, for the high temperature compressor, ethylene and ethane pairs have $12 \%$ and $15 \%$ lower irreversibility than R404a $\mathrm{R} 508 \mathrm{~b}$, respectively. For the low temperature compressor, ethylene pair has $7 \%$ greater irreversibility and ethane pair has $2 \%$ lower irreversibility than R404a - R508b. The added exergy destruction of ethylene and ethane pairs are $7 \%$ and $12 \%$ lower than R404a - R508b, respectively.

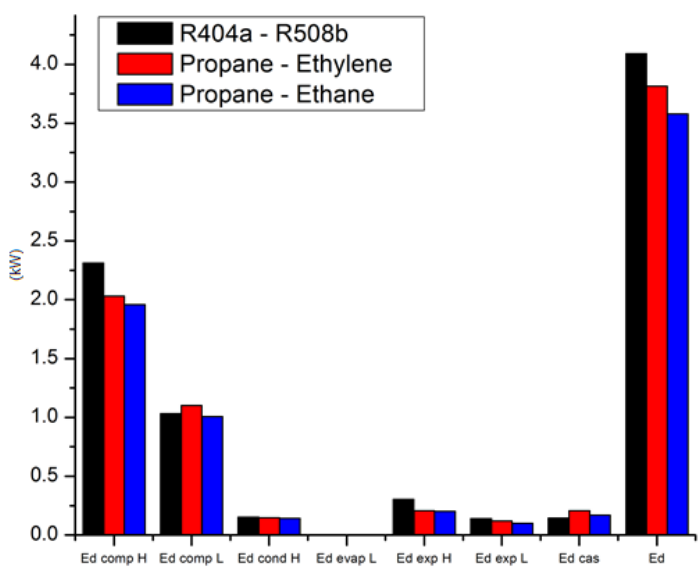

Figure 4. Irreversibility per component and total irreversibility

Fig. 5 shows coefficient of performance per cycle and cascade system's coefficient of performance, all per fluid pair. Results at Table 1 and Fig. 5 show that HCs' coefficients of performance of the high temperature cycle $(\mathrm{COPH})$ are $16 \%$ better than $\mathrm{R} 404 \mathrm{a}$ - R508b. For the low temperature cycle (COPL), ethylene's pair is $4 \%$ worse, and ethane's is $4 \%$ better than R404a - R508b. Cascade system performances (COPcas) of Propane - Ethylene and Propane - Ethane are $8 \%$ and $13 \%$ better than the synthetic pair's, respectively.

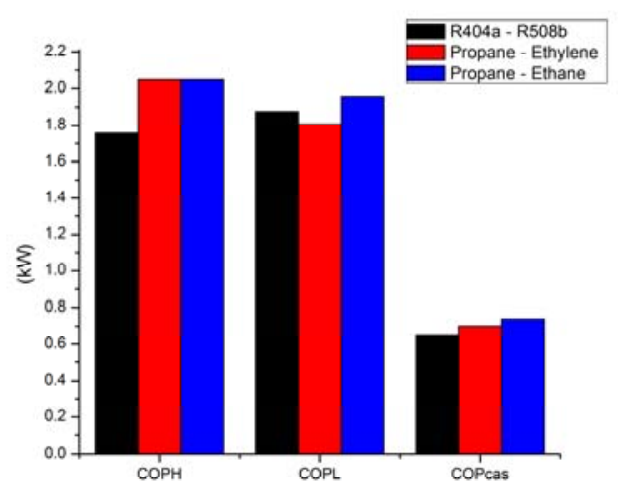

Figure 5. COP per cycle and for cascade system

\section{CONCLUSIONS}

In this work, a theoretical and numerical study was conducted using modeling and simulation, to demonstrate that natural refrigerant fluids like hydrocarbons has better performance than synthetic fluids in ultralow freezers applications, with cascade refrigeration cycle.

As seen in results section, HCs fluids consume $7 \%$ to $12 \%$ less energy for the same amount of cooling power and present $12 \%$ to $15 \%$ lower irreversibility.

They have a linear growth of energy consumption with growing condensation temperature 
while R404a - R508b presents exponential growth for high temperatures, meaning $\mathrm{HC}$ have better performance for very high temperatures; they have better overall coefficient of performance.

Comparing both $\mathrm{HC}$ fluid pairs tested, the one that shows better results, less energy consumption and irreversibility is propane-ethane.

Environmentally speaking, HCs are way less aggressive to the ozone layer and greenhouse effect, as they offer zero Ozone Depletion Potential (ODP) and have a Global Warming Potential (GWP) near 3, while R404a - R508b have GWP 3920 and 13396 respectively.

\section{REFERENCES}

Park, H.; Kim, D. H.; Kim M. S., 2013, Thermodynamic analysis of optimal intermediate temperature in R134a-R410A cascade refrigeration systems and its experimental verification. Applied Thermal Engineering 54: 319-327.

Bayrakçi, H.C.; Özgür, A. E.,2009, Energy and exergy analysis of vapor compression refrigeration system using pure hydrocarbon refrigerants. International Journal of Energy Research 33: 10701075.

Ahamed, J. U.; Saidur, R.; Masjuki, H. H., 2011, A review on exergy analysis of vapor compression refrigeration system. Renewable and Sustainable Energy Reviews 15: 1593-1600.

Alhamid, M Idrus; Syakra, Darwin R.B.; Nasruddin., 2010, Exergy and energy analysis of a cascade refrigeration system using R744+R170 for low temperature applications. International Journal of Mechanics and Mechatronics Engineering, 10.

Aminyavari M.; Najafi B.; Shirazi A.; Rinaldi F., 2014, Exergetic, economic and environmental (3E) analyses and multi-objective optimization of a $\mathrm{CO} 2 / \mathrm{NH} 3$ cascade refrigeration system. Applied Thermal Engineering 65, 42-50.

Di Nicola, G., Polonara, F., Stryjek, R., Arteconi, A., 2011, Performance of cascade cycles working with blends of $\mathrm{CO} 2+$ natural refrigerants.International Journal of Refrigeration, 34: 1436-1445.

Kilicarslan, A., Hosoz, M., 2010, Energy and irreversibility analysis of a cascade refrigeration system for various refrigerant couples. Energy Conversion and Management, 51: 2947 - 2954.

Hwang Y.; Jin D.; Radermacher R., 2007, Comparison of R-290 and two HFC blends for walkin refrigeration systems. International Journal of Refrigeration 30: 633-641.

Corberán, J. M; Segurado, J.; Colbourne, D.; Gonzálvez, J., 2008, Review of standarts for the use of hydrocarbon refrigerant in $\mathrm{A} / \mathrm{C}$, heat pump and refrigeration equipament. International Journal of Refrigeration 31 :748-756

Kabul A., Kizilkan, O., Yakut, A. K., 2008, Performance and exergetic analysis of vapor compression refrigeration system with an internal heat exchanger using a hydrocarbon, isobutane (R600a). International Journal of Energy Research, 32:824 836.

Fabrega, F. M., Rossi, J. S.; d'Angelo, J. V. H., 2010, Exergetic analysis of the refrigeration system in ethylene and propylene production process. Energy, $35,1224-1231$.

Kotas, T. J., 1995, The Exergy Method of Thermal Plant Analysis, University of London, England,

Szargut, J.; Morris, D.; Steward, F., 1988, Exergy analysis of thermal, chemical and metallurgical processes.1st ed., Chem/Mats-Sci/E. New York, EUA

Palm, B.., 2008, Hydrocarbons as refrigerant in small heat pump and refrigeration systems - A review. International Journal of Refrigeration 31: 552-563.

Hansen, T. M.; Haukås, H. T., 2000, Alternatives to HCFC as refrigerant in shipping vessels. Nordic Council of Ministers, Copenhagen.

ASHRAE, 2000, American Society of Heating, Refrigerating and Air Conditioning Engineers.ASHRAE Application Handbook-HVAC. Atlanta. 